\title{
The Myth as a Tool for Human Behavior Setting
}

\author{
Pasquale Scarnera ${ }^{1}$ \\ 1Social Cooperative "Questa Città", Gravina in Puglia (BA), Italy. \\ Correspondence: Pasquale Scarnera, Clinical Psychologist-Social Cooperative «Questa Città», Via Guardialto, 8-70024, \\ Gravina in Puglia (BA), Italy.
}

Received: April 29, 2016

doi:10.11114/ijsss.v4i7.1612
Accepted: May 15, 2016

Available online: May 16, 2016

URL: http://dx.doi.org/10.11114/ijsss.v4i7.1612

\begin{abstract}
For different reasons, the psychoanalytical and structuralist models of analysis of the Myths fail to provide satisfactory explanations of methods by which the ancient myths have managed to remain in time and spread in space, although not possessed any organizations specially designed for this purpose. Discussing the literature most salient on this topic, the present work identifies the conceiving and enjoying features that may help to explain this phenomenon, including the production of numerous variations which characterizes the myths in time and space without substantially altering their identity, at the same time making the production and use of Myths an extraordinary instrument of psychosocial adjustment of the Community to which they relate. The analysis of the Prometheus/Origin of Mankind Myth is then proposed, within a model that attempts to furnish explanations more satisfying.
\end{abstract}

Keywords: Psychoanalysis, Structuralism, Myth, Behavior Regulation

\section{Introduction}

Society operates in a quite ordered and predictable manner, although not always its components are aware of the rules and sanctions governing its functioning. This evidence is even surprising in the case of the mythical and religious beliefs, which do not provide a system of penalties and rewards that promotes their recognition, acceptance and maintenance by the components of the Community to which relate. Explain such evidence is therefore important for the understanding of the way in which societies operate. In this regard, the psychoanalytical and structuralist models of analysis offered extraordinary contributions to the understanding of human behavior, without however being able to fully explain this phenomenon. It is therefore necessary to revise these interpretative models and methodologies of analysis developing more appropriate ones, which allow both...better interpret myths and religions explaining their function in society to which relate, than better explain their permanence and propagation in time and space. This better adequacy, in fact, could also prove... useful in decoding the modalities of permanence and change of other types of social process.

\section{Discussion of Theoretical Perspectives}

\subsection{Psychoanalysis}

The psychoanalytical model, at its inception traced back the presence of mythical - religious beliefs to an undefined form of inheritance, at the same time genetics, cultural and psychological (Corbey R., 1991): S. Freud believed that the $I d$, the primitive unconscious not yet modeled by educational processes and by repression, was a product of the repetition of archaic experiences, transmitted in the genetic code of the humankind, which prepares individuals to reproduce in a similar manner both certain psychical structures (such as the Ego and the Super-Ego), that certain beliefs (Potschka M., 2004). According to S. Freud, these similarities could be explained according to the same methodology already described in the Interpretation of Dreams (Freud S., 1899). According to this model, the community carried out conflicts altogether similar to those that the child crosses and removes during his childhood in respect of parents, leaving them in latency for a certain period, and feels them reappear in the form of psychopathological symptoms in adulthood: in this way, primitive hordes, which killed their leader to mate with females from the same leaders prohibited them, would have established, pressed by a sense of guilt and by sexual rivalries, totems that confirmed the prohibition of incest (Freud S., 1913). The same oedipal structure would be at the basis also of the monotheistic religions, in which the leader killed would just reappear after a period of latency in the iconography and mythology of reference (Freud S., 1939).

Were applied to the mythology even the theoretical post-Freudian developments, also using the discoveries relating to 
the development phases of the primary pre-oedipean psychic development of child, and those concerning the internal dynamics of the same psychoanalysts, determined by the reactions and interpretive deformations shaped in relation to the symptoms of the patient. Therefore, in the current state, the psychoanalytical orientation toward the mythology can be synthesized in the use of the following approaches (Vandermeersch P., 2001a ):

A. direct to the hidden content of the text, focusing at a oedipean level;

B. direct to the hidden content of the text, focusing at a pre-oedipean level;

C.direct to the response of the reader, focusing at a oedipean level;

$D$. direct to the response of the reader, focusing at a pre-oedipean level.

The interpretive distortions produced by the reactions of the reader (points $C$. and $D$.) can be controlled by analysis of content similar to these interpreted (i.e. checking if the proposed interpretation of a given passage is consistent with those derived from further steps of the same myth or other thereto congruent), and/or by controlling ... the historiographic plausibility of the interpretations proposed (i.e. by assessing whether the proposed interpretation is contradicted by other historical data), however the interpretation developed in respect of the text (points $A$. and $B$.) does not differ from the Freudian ..., except for the addition of the pre-oedipean level (Vandermeersch (P., 2001b).

S. Freud believed that religion was based on a denial of reality and illusions of satisfaction of desire similar to those found in the amentia, and that it represented the obsessional neurosis of humanity, born from the oedipean complex linked to paternal relationship, destined to be abandoned as well as the child leaves, during growth, its own neurosis, contracted because of mental immaturity that characterizes the childhood (Freud S., 1927). The Anthropology derived from such a model then investigates the human nature from its pathological variants, therefore considers the mythical-religious beliefs of a people as an expression of its pathology (Van Haute P., 2005), destined to disappear as disappears the neurotic symptoms, once freed the repression.

This conclusion gives rise to a certain doubts because the neurosis, by definition, are a source of suffering and are not adaptive therefore have little chance of success in the adaptation and tend to become extinct. Instead, myths and religions persist and spread in a wide variety of different historical, geographical and cultural contexts. Furthermore, although revealing the origin of neurotic symptoms as emerging from incestuous and death desires toward their parents, you can reach the disappearance of repression and neurotic symptoms; however this disappearance does not include that of sex and death desires of person. In the same way, revealing the oedipean structure of a religious building, as done by S. Freud in quoted essay, does not automatically lead to the disappearance of desire (or need) of religious transcendence. It therefore seems that Freud, in his essay, has mistaken the shape that one religion can assume with its substance.

The underestimation of this factor, together with the excessive emphasis on the presumed pathological aspects of the mythical creations, has emptied the interpretive potential of psychoanalysis, by transposing the mythical imagination in a reassuring register of truth, familiar and well-known methodologies, to the point that every element present in the mythical constructions is considered a representative of sexual impulses, murderous or incestuous, although these creations speak often and openly of castration, incest and parricide (Sels N., 2011).

This emptying can be explained as an example of deformation due to the reaction of the reader, not figuring it in an oedipean or pre-oedipean level, due to improper transposition of approaches and attitudes, effective within a given interpretative context and manufacturing process, on another which differs substantially from them: the Institutional Transfer., that is a phenomenon originated from current phantasmal social and productive relations, rather than interpersonal lived in the past, like the oedipean and pre-oedipean transfers. This operating mode reproduces the phantasmal configuration that regulates the social relations within a given manufacturing process and organizational context (Carli R., 1987), organizing the emotional relationships in a manner consistent with the characteristics of the productive structures, roles and functions within which relationships are built, ritualizing conflicts and ensuring the emotional control (Carli R., 1984). However, this valuable feature of the institution can become an obstacle that may affect significantly the validity of both the representations/interpretations of data and contexts, than of behaviors to them consequent, when the differences between data and contexts are not carefully assessed.

\subsection{Jung's contribution}

According to C. G. Jung, unlike S. Freud, the mythological production, which he studied in both people suffering from mental disorders that in the mythical/religious symbologies throughout the world (Jung C. G., 1912), is not to be considered as symptomatic expression of mental conflicts: the continuous repetition of certain experiences would have bring to formation of Archetypes, forms without content adapted to represent only the possibility of a certain type of perception or action, that are activated also providing psychic energy specifically oriented toward certain situations, independently from the person's will or reasons (Jung C. G., 1936). The archetypal region is subsided in the Collective Unconscious and is independent both from the neurotic conflicts than from the region of the Individual Unconscious, 
which is more superficial; it produces ideas and performances endowed of a numinous charge that activate the person regardless of his will, causing a particular change of consciousness (Jung C. G., 1937).

Nevertheless the Jung's interest for the symbolic productions of Mythology derived from clinical contexts and remained confidential to them. In fact, he considered that it was not possible to provide exhaustive explanations of an archetype, and that its interpretation had to be contextualized in a way consistent with the situations and the needs of the person analyzed (Jung C. G., 1940), considering the mythological production as a resource to be used for the treatment of individual disorders, since it is not possible to escape from archetypal psychic production, without to run into the neurosis (Mills J., 2012).

\subsection{Common aspects within Freud and Jung}

Both the Freudian than Jungian position argue that the experiences made by humanity as a whole can be handed down through somatic components that translate them into actual psychic experiences. This process of transformation of the experience in the genetic code, as explained by G. Bateson, would not be adaptive, since it could not provide adequate responses in relation to the changing contexts, condemning people to repeat experiences, originated in the past, that are not related with the present context. In fact, has many more probability of success the adaptive capacity to fit with success, through a series of assimilations, adaptations and adjustments, within different environments, rather than the ability to automatically adapt to a predetermined context (Bateson G., 1963).

Therefore, in the absence of a genetic substrate, it must be concluded that the archaic symbolizations which psychoanalysis is able to identify and decode, in present, are generated in the present observed, without any relationship with the experiences made in the past by the humankind and/or of the community of reference. Alternatively, it must be assumed that the symbolic archaic productions detected in the present can be reached from the past within which were originated, through different processes from those inscribed in the genetic code.

\subsection{Lacan's contribution}

According to Lacan, human experience is characterized by a discrepancy between the experience of the person and the process of symbolization, that develops on three different levels:

- on Imaginary level, between 6 and 18 months, when the child, by having a fragmentary perception of itself, and unitary self-images reflected by external objects with which he identifies itself, obtain an .. unitary image, which however is alienating, since it is confused with self fragmentary perceptions, and even rival with these latter, because discordant to them. At this level is therefore always present a certain degree of non-correlation between images of self (the self perceived and reflected one..), that is a source of frustration and aggressiveness (Lacan J., 1949)

- on Symbolic level, during the learning of the Language, that is a communication system based on signs that must be ordered in a syntactically correct manner in order to fulfill its communicative function. The signifier, during this phase, is prioritized, because the concepts to which signs refer can be explained and understood only through other signs, which refer to other concepts, in an infinite chain of signification. The signification process is then continuously, and comprises an unceasing production of new signs that are capable of mean concepts not yet subsumed inside available marks, while communication occurs within anchor points between the universe of significant and background of amorphous mental material pending signification, constituting moments of stable signification. This means that, for Lacan, once acquired the language, everything is structured and ordered in a manner thereto conformed, included the unconscious and human subjectivity. Since the language is a Tran-personal structure, which preceded birth of people and continues to exist after their death, the acquisition and presentation of identity and human subjectivity is conditional to the acquisition of the same, i.e. the Symbolic Order established by it, never completely acquired and subject to continuous transformations. The institution of the symbolic order is also constructed by the system of relations established between signs, which include both the rules of semantic than grammatical oppositions, without however identify themselves with the same. That is to say that the same subject, the identity of persons, acquires a meaning in the same way as the other signs, i.e. by opposition to other signs and relationship with other significant (Lacan J., 1956; 1957). Therefore the subject can never find a stable representation, because the symbolic order that defines it also antedate it and does not possess a representation stable and predetermined, valid for all contexts. However, acquiring the language the person acquires the oedipean structure, because he must necessarily compare him desire with the desire of the other through language, that is a trans-personal instrument acting as a third element (the rule, the law, the inhibition, the prohibition) which affects relations (Lacan J., 1958). For Lacan, then, differently than to S. Freud, it is not necessary to postulate a phylogenetic inheritance of the Oedipean Structure: to be inherited is the ability to acquire the language, whose internalization involves the formation of the Oedipean Structure, which therefore promptly and automatically appears in both the linguistic than mythological production

- on Real level, in the unknown world, perceived at the pre-symbolic level and not described by the signifier chain, 
which manifests itself through the need, founding the reality as defined socially from the symbolic order, without being able to identify with it: as thing in itself, in fact, the real lies beyond any attempt to description through signs or images (Homer S., 2005).

This situation, for Lacan, is constitutive of the Unconscious, which manifests itself in the Symbolic Order being inserted in the distance that separates the signifiers from meanings, among the slipping of the meanings under signifiers, and in the impossibility of the symbolic order to be fixed and predetermined. This means, for Lacan, that the unconscious, although .. is insuppressible, has not hereditary content. In fact, although instituted by imaginary and interpersonal, as well as trans-Personal and symbolic dynamics, for Lacan the Unconscious remains individual (Lacan J., 1953).

Further explore this condition, for Lacan is useless: posing the question of the origin of language might lead to a organized collective delusion, because it would not be possible to know when it began and how things were back before the appearance of Language (Lacan J., 1953c). In fact, it is not possible to know the state of things, as they were before the appearance of language. However contemporary scientific researches as well as psychoanalysis to the times of Lacan, have established the existence and effects of communication already before the acquisition of language. The ability to understand the mental state of the other has also been studied by techniques of Nuclear Magnetic Resonance, which revealed the activation of the same cortical regions (Sensory-motor, Limbic, and Para- limbic) in both people that feel an emotion in a direct manner, original, than in other, that feel the same in an empathetic, derived manner. The same survey methodology have clarified the difference between the understanding of emotional states and that of other mental states experienced by people with whom one is in relation, connected to the pursuit of objectives, beliefs and intentions, involving activation of Prefrontal Regions and Temporal Lobe, which mature very after, preceding these responsible for empathetic comprehension (Singer T., 2006): the ability to understand emotionally, then, is acquired before that to understand through language, and it also makes possible the acquisition of language: in fact, the association between a linguistic sign, the concept and the referent to which it refers is learned, from the infant, in contexts in which the emotional signification, both of the concept than of the referent, is shared before the appropriate linguistic sign, introduced by the adult, intervenes to denote it. Moreover, the empathetic perception and awareness of the emotional states of others is settled especially in the right hemisphere, that matures before the left .., and is dominant up to the age of three years, when the linguistic capacities, expressed predominantly from the left hemisphere, begin to express themselves also through the narration of stories (Schore A. N., 2000). It is therefore correct to assume that the institutionalisation of the (new) linguistic signs is derived from similar processes, in which two or more (pre) speakers associate an emotional connotation and a concept to a linguistic sign expressed, even accidentally, from one or more speakers. Differently, in a context in which language is dominant, the institutionalisation of a new sign take place through the use of other signs that describe the concept and the referent to associate with it.

Therefore, in the extent to which it is correct to assert that the Ontogenetic development recapitulate that of the phylogenetic ..., and that the paths of Individual Ontogenetic Development are parallel to those of the Phylogenetic Development of Mankind, it must be concluded that the human race .. have passed through periods in which the emotional understanding of the world prevailed on that logic, as expressed through the language. Or, alternatively, that the emotional understanding of the world has had (or have) a weight greater than you are willing to believe. The psychic and existential dimension wherein the mental processes are characterized by the dominance of the emotional thought on the logical .., can thus be considered one of the Creative Matrices of mythological production.

According to Lacan, the unconscious is a Removed Unconscious, that can be decoded using the Freudian model. However Lacan is distance from Freud on some of the conclusions of the general order: apart from the different theory on the acquisition of Oedipean Structure, Lacan believed that religion was irrepressible, as essential in order to give meaning to human concerns, although strongly determined by the scientific knowledge (Lacan J., 1974).

\subsection{Structuralism of Lévi-Strauss}

The Anthropology of Lévi-Strauss is inspired to F. de Saussure's linguistics, according to which the linguistic sign represents a unit between Concept and Sound-Imagine, rather than between thing and name, and is characterized by the general arbitrariness of the relationship between Signifier (sound-imagine) and meaning (Concept), therefore there are no concepts or natural categories, which are simply reflected in the language, then this plays a crucial role in building the reality because, giving a name to the concepts, prepares a common signification of reality for the speakers. (Chandler D., 1994).

According to Lévi-Strauss. such arbitrariness is fundamental in the anthropological studies because at every act of communication remains subtended the recognition that there is something more to mean, with respect to what has been signified, and that at every experience corresponds the feeling of not being able to describe for entire the same through signifiers. Experience and communicative act are thus characterized by the insistence of the unconscious in the consciousness; therefore the cultural production of a people is defined by the specific solutions with which it seeks to 
overcome the discrepancy constituted by the relationship between the experience of the person and floating signifier (Mehlman J., 1972). For what concerns the mode of thought of the Primitive Peoples (or Peoples Without Writing), it would differentiate from scientific thought because it tries to reach the general and total understanding of the universe in the shortest possible time, being regulated by an axiom that predicts that we cannot explain anything without having understood before everything, to the contrary of scientific thought that seeks to give explanations which involve a limited number of phenomena, then seeks explanations for other phenomena (Lévi-Strauss C., 1962). A typical mode of pursuing this goal is represented by translating images drawn from the perceptual experience, sensory/explanations that relate to the phenomena of the universe, that this experience escape (Lévi-Strauss C., 1977).

\subsubsection{The analysis of the myths according to Lévi-Strauss}

Lévi-Strauss believed that music and myth originated both by language, stressing, respectively, the sound and the sense, that are already present in the language (Lévi-Strauss C., 1977); however he was interested to the significant structure of the myth, more that the meaning that the various myths take within the cultures from which they come. The Primitive Thought creates myths by classifying the phenomena according metaphors, analogies and metonymies, unlike the scientific thought, that ranks the same for mutually ruled out classes. This classificatory mode contains parallelisms with cultural practices in action that associate Totem and Myths to life styles of culture that produced them (Lévi-Strauss C., 1962), however the Structuralist analysis of Lévi-Strauss, also within the extraordinary work of cataloguing and analysis of myths collected in his Mythologics, does not seem to be particularly interested to this relation, because it is mainly oriented to describe the transformations of the various myths in time and space, identifying the unconscious rules that tend to reconstruct a unity between phenomena, typical of the natural existence, that is lost with the advent of the cultural existence (Lévi-Strauss C., 1964; 1967; 1968; 1971). This reconstruction takes basically place trying to overcome the original opposition between nature and culture by other oppositions which however cannot solve the first, leading to a continuous reinvention and redefinition of the same Mythemes (Clarke S., 1981). This work of continuous regeneration, however, comprises the reworking of the same modes of thought: in fact, the analysis conducted in the Mythologics presents the Primitive Thought as a precursor of the Logic, Scientific and Literary Thought, as respectively manipulator of shapes, quality and stories.

The methodology of analysis proposed for the Myths of peoples equipped with writing (the Myth of Europa and that of Oedipus, produced from the ancient Greek Civility) consists in disposing the sections according to both a diachronic than a synchronic order, as occurs for the musical partitions, without confusing the levels of analysis of the Myth with those of analysis of the structure of the language (Lévi-Strauss C., 1955a). In fact, the language through which the Myth is expressed may not submit synchronously the Mythemes, although the speakers (or analysts) may do so because of their feedback of knowledge: the synchronic associations between Mythemes represent the products of knowledge and memory, as well as built and shared among the speakers (or among analysts), not the language (written or spoken) through which Myths are expressed. Therefore, although the analogy between linguistic structure of the music and the model of analysis of the Myth can lead to the identification of suggestive liet motif (that is, Mythemes which are repeated between different Myths), it is completely artificial and instrumental to the understanding of the mythical mentality, thus it cannot be inscribed within the narrative structure of the Myth. Therefore, although the author has recognized the crucial role of writing in the formation of states (Lévi-Strauss, 1955b), the underestimation of the impact that the invention of the writing could have both on cultural production than on a sense of historical identity of a people, has led the author to consider the myth of Europe and that of Oedipus (together with many others mentioned in the same work), as variants of the same myth, identified however with the Mythemes that constitute them, neglecting, in fact, the evidence that they were stories very different, therefore with different meanings and senses. Especially the Scripture, indeed, has the potentiality to make independent from the relational and spatio-temporal contexts the contents transmitted with the communication, facilitating the meta-linguistic use of the language and therefore the processing of second level abstractions and symbolizations, even different from those of Thought both Primitive than Scientific.

Furthermore, Music differs from the language, besides for the use of notes instead of phonemes, for the possibility of combining synchronously more notes, while the myth differs from it, besides for the use of phonemes in place of the notes, for the referent and for the meanings to which belongs, as occurs for all languages: there can be no language outside of the ties that bind the speakers among them, the referents to whom they are addressed and the code used to communicate and adjust their interactions and actions. In fact (Schneider M., 1970; Collisani A., 1988; Imberty M., 1990), musical synchrony and diachrony, like all languages, obey to rules of linguistic composition and refer to something else, external and/or internal, although this "something else", as rightly pointed out by the author (Lévi-Strauss C., 1971, 1977), cannot be systematically translated (that is, according to rules that allow to obtain similar translations from different people), in words, images and/or other sounds. To assert, then, that myths and music cannot be translated through a language different from that from which are expressed (Del Ninno M., 2010), seems to underestimate an important aspect of both the myths than music: both produce, like the other languages, effects on 
listeners; because where there are effects there are also meanings, the difficulty or impossibility to translate from one language to another (then explain the meanings of Music or the Myth with other languages) does not imply that one or the other of the languages is not a bearer of meanings, then refer to referents, and their sense to a relationship between these and the speakers.

\subsubsection{Lévi-Strauss and Psychoanalysis}

Although Lévi-Strauss thought that Psychoanalysis of S. Freud had had the great merit of detecting that the irrationality of the dream was explicable in rational terms, he did not accept that the principles of psychoanalysis were used in anthropology because relating to a specific category of dream, referring to the unconscious desires, which does not include other different categories of dream. He did not accept even the concept of Collective Unconscious proposed by Jung, because he believed that in origin every story was invented individually by a person, and the story became a myth only when it was accepted by the reference group, formed of individual minds that operate in the same way and that coexist in the same society, entertaining with the natural world the same relations, then turning into myth what was once a dream (Bucher B., Lévi-Strauss C., 1985). The process of this transformation, however, remains quite vague.

\section{The adjustment of the behavior by language}

The social reality can be articulated and transformed, satisfying needs, intentions and desires, with the action or with the communication. In a social context, however, also an isolated action acquires communicative value, since necessarily assumes a meaning for the observers present in that context. In fact, according to the Axioms of Communication, it is impossible not to communicate. Moreover, since the communication always transmits messages related to both the content of the same than the relationship between speakers, and that the latter is always symmetric or complementary, the communicative act always implies a hypothesis of adjustment of the relations between the speakers (Watzlavick P. Eavin, J.H. and Jackson D.D., 1971).

\subsection{The Paradox of Communication}

However it is not granted that relations between the speakers will lead to the development of a stable organizational structures, which then meet the aims that the speakers are pursuing: indeed, these may be different for each speaker, then it would not be possible to build an organization with unique purposes on the basis of the individual personal goals. Thus the construction of social systems, which as such pursue the goals of collective interest, according to these axioms occurs in a random manner, although it is useful and necessary. This paradox was studied by analyzing the philosophical Systems of Integration, of Oriental Application, and of Complementarity, of Western application (Apel K. O., 1977).

The Integration System considers a natural law the symmetric opposition of various thesis and antithesis produced by thought, as expressed through the various actors interacting in reality, and therefore it proposes to overcome contradictions and conflicts present in human relations through the synthesis of contrasts by an elite (philosophers, heads of every kind and degree), which assumes the guide of the various social contexts and ensures the rationality of the choices and operations of the social system by integrating science and ethic. However, in making operational (ordering) its determinations, cannot reconcile its decisions with those of the individuals.

The System of Complementarity recognizes as a natural law individual differences and therefore maintains the field of choices within the freedom of the private sphere, and founds the intersubjective validity of ethical standards through the not-evaluative and scientific description of the consequences of the actions by means of rules of the type: if ... then ... but this operation, carried out by technicians in respect of profanes in a complementary manner, may not base, in the latter, the sense of responsibility necessary to take those decisions that were implicitly envisaged as necessary, on the basis of the scientific rationality.

Paradoxically, the strategic resolution of Integration System is proposed as a complementary construction between management and subordinates, and the existential solution of the System of Complementarity is proposed as a construction that opposes symmetrically individuals with equal rights, with regard to decisions to be made: the point of arrival of one comes to coincide with the starting point of the other, therefore the two systems may be considered to be the expression of two or perhaps the same vicious circle. According to the Ordinary Logic, then prescribe ethical standards or behavioral is impossible. In fact, Apel does not solve the aporias highlighted. Therefore, in the light of its analysis, we should expect fewer societies how much actually we find. Instead, both groups and organizations exist and function in a manner quite ordered and articulated, although prescribe the rules to obtain this result is impossible, according to the Ordinary Logic.

According to this logic, the rule: by one-self, solves the aporias in both systems, from the moment that a system can be constituted from at least two persons. In addition, as decisive moment of solution of a systemic aporia and of the same system, constitutes the necessary condition for recognition of the other as different and independent from oneself, and 
as an agent in itself and for itself. However, while providing a systemic solution, this rule cannot achieve those transformational intentions which can be pursued only through the articulation of own actions with those of others. Therefore, since it is not possible to explain the operation of an interpersonal relationship, of a group and/or an organization apart from the individual processes activated between its components, it is necessary to postulate the existence of a regulatory parameter, operating in the minds of individuals, explaining the consistent and unidirectional operations of groups and organizations, irrespective of the various systems of deterrence and reward specially developed for this purpose: in fact, there are groups and organizations that work even in the absence of regulations and contracts. Starting from the solution of aporias, there are four possible alternatives:

1. to abandon the system of reference;

2. to renounce to own intentions that do not coincide with those of the reference system;

3. build the necessary conditions to which a system, of Integration or Complementary, functions: i.e. that exists, on the part of the interacting, a substantial sharing and/or identification in the hierarchical organization of the system, in a Symmetric version, or a sharing of values and/or of the aims underlying the decisions to be taken, in Complementary version. The results which can be achieved with the discussion, in the System of Integration, and with the control of the Authority freely recognized, in the System of Complementarity. Basically, considering both systems, through a communicative mode aimed to seek and obtain the consent;

4. be there, without remain (examples of such solutions are satire and irony which, although alluding to possible alternative scenarios to the target, does not necessarily imply the assumption of direct and consequential responsibility, with regard to the actions to be performed to obtain a change from part of the person who creates the satire and/or ironizes.

Solutions 1 and 2 represent the positions that are more appropriate to maintain the constancy and the identity of the cultures in time and space, while solutions 3. and 4. those more suited to manage the cultural changes, whether it is to change an attitude by the same people who have previously built, or it is to change an attitude on the part of strangers to its previous constitution. However, such solutions may not be prescribed in no way, as are the conditions to be found, remain and be renewed daily to the work of individual social actors concerned. They therefore represent a method to search for solutions (and not a solution), regulated by the Ordinary Logic.

\subsection{The ephemeral solution of the Unconscious}

However, the human relationships are not adjusted only by this logic. The human mind, in fact, also operates through the Logic of the Unconscious System, which is emotional, symmetrical and, contrary to the Ordinary Logic, which is asymmetrical, dividing and generating differences, gives rise to a mode of thought homogeneous and indivisible.

This mode of operation belongs both to the Removed than Systemic Unconscious, and is regulated by two principles: the Principle of Generalization processes one thing individual (person, object, concept) as if it were a member or an element of a set or a class that contains other members; treats this class as a subclass of a more general class and this more general class as a subclass or a subset of a class still more general and so on (in an infinite way), selecting those propositional functions that in one aspect express a general growing and in other retain some special characteristics of the individual thing from which are originated (Matte Blanco I. 1981). The functioning of this principle implies that anything a person performs in reality is meant both for itself, through the Language and the Ordinary Logic, that for something else, through the Logic of the Unconscious System.

Both the signification process products from the Language than derived from the Principle of Generalization may not therefore that operate at an unconscious level: as an expression of relations that extend their self in an infinite way, it pertains to a model of operation that cannot be contained in the Conscience, which can operate only on a finite size. However, the concept of the Unconscious is not the same for the two processes of signification: the Principle of Generalization belongs to the mode of emotional signification, while that of the infinite network of semantic contrasts belongs to the Ordinary Logic. The signification process operated by the Principle of Generalization therefore consists in allocating an emotional valence to perceptions or logical representations, which would otherwise be neutral from the point of view of emotional connotation of their semantic content, and arbitrary, from the ontological point of view: Indeed, the distinction between the subject and the object is arbitrary, since both entities belong to the same status of being object; being arbitrary this fundamental distinction, also all the others are.

The Principle of Symmetry treats the inverse of any relation as if it were identical to the same relation, processing the asymmetrical relations as if they were symmetrical (Matte Blanco I. 1981). In the Symmetric Logic, therefore, prescribe ethical standards is not feasible because the principle of symmetry does not represent causal successions, then it is impossible to criticality assess the situations in act anticipating future developments, as well as the effects of the possible remedies. The Symmetric Logic, however, orients socially the action in the communicative interactions. In fact, 
by treating the relationship as being identical to its opposite, so making symmetrical the asymmetrical relations, the principle of symmetry introduces in asymmetrical relations the emotional assessment of the position of the other, mocking unconsciously the logical aporias through the mechanism of identification; or, when the aporias are aware, by adjusting the communication in order to obtain the consensus on the rules to be followed, or by changing the purpose and/or communication strategies. Therefore, in developing strategies in accordance with the solutions 3 . and 4 . above described, the method of integration between the two logics may lead to symbolic productions which pursue the same objectives pursued through the search for consensus through discussion, i.e. mainly through Ordinary Logic, on the basis of mainly emotional productions, i.e. through the Symmetric Logic. The phenomenon of empathy (Stein E., 1917) illustrates perfectly the Principle of Symmetry, since through it are accomplished the emotions performed by the person with whom you deal, although it is differentiated.

The third principle proposed by Matte Blanco says that every product of the mental activity is made by some form of integration between the two logics (Matte Blanco I. 1981). In the absence of integration, in fact, there could be no mental activity: although the Emotional Logic of the Unconscious System cannot allow any action nor thoughts oriented to a conclusion (the Principle of Symmetry does not think temporal successions, spatial and causal relationships, while the principle of generalization requires that each object is perceived meaning as something else, in an infinite way), connoting emotionally every perception, arranges the ontological arbitrariness that characterizes the distinctions drawn up by Ordinary Logic, giving a meaning to each object and a sense for each action. Conversely, the Ordinary Logic allows the motivational drives originated by the emotions to achieve the objectives which allow to satisfy needs and desires.

\section{Language and Knowledge}

The structure of the language allows you to sort the chaos resulting from the arbitrariness of the distinctions drawn up by Ordinary Logic: the language, in fact, provides verbal or written versions of mental representations. Every mental representation, in general, is representative of something, then is a knowledge of something. From a purely social point of view, knowledge that are not widely used have a reduced value because die together with the subject that hold them. On the other hand, do not disseminate knowledge would entail a perennial zeroing of history, which should start every day from the zero point, with severe disadvantage for both individuals than communities. They are therefore, socially valid only the knowledge that possess the characteristics of the diffusibility.

To be diffusing, knowledge must consist in an accurate description of the phenomenom and of the practice to spread, in order to allow a third party to identify the former inside the universe of observable phenomena, and duplicate the latter in space and time. To be describable to third parties of the experiences and procedures underlying the knowledge, in turn strengthens the principle of the recognition of the differences between the phenomena and the relationships that connect them, allowing to evaluate the quantitative entities of the phenomena object of knowledge, and then to measure their socio-economic weight. In other words, to be describable, that is the translation process of thought in language, allows you to evaluate, in the first instance, if the phenomena object of knowledge are quite interesting, popular and important, to the point to justify the use of the energy required to acquire their knowledge and transmit it. Therefore the language would fail in performing its function of dissemination of knowledge, if it does not come to a satisfactory level of conformity between the needs and expectations of the different speakers and surrounding reality. In fact, the description of phenomena and relationships between non-existent phenomena or of little interest would not be reproduced, and the description of ineffective and/or inefficient practices would not involve social reproducibility: the transmission of knowledge implies primarily a passage from micro - social level of perception and representation of the phenomena and of knowledge (and their evaluation), to the macro - social one.

However, the linguistic constructions are subject to errors, corrections and revisions, and the emotions are fickle, impromptu and unstable. Therefore, if on the one hand the intersect of two logics makes possible operation of thought, on the other hand cannot generate any mental construction that is stable and definitive. Therefore the thought and its same plasticity are possible if the relations that found the distinctions, giving them a sense and meaning, made by the Ordinary Logic, have constant characteristics, at least relative: this stability of reference allows the apparatus to think to constitute itself and to carry out its function within the body that generates it: in fact, thought would fail in its function of adapting to the real if the distinctions on which it is based were to vary continuously.

The consistency and the meaning of our thought, ultimately, are caused by factors of which we are not aware of: the only Ordinary Logic does not allow to implement actions because cannot define any purpose, while the Symmetric (or Emotional) Logic does not allow to realize actions why cannot advance any. This means that, within individuals, the model of integration between the two logics should maintain characteristics of constancy and invariance, in time and space, at least relative: the absence of stable integration between the two logics, in fact, would make impossible both the thought than the action. 
For Matte Blanco, the integration of the two logics initially occurs through the lateral insertion of the instinct, that is species-specific stereotyped behaviors, oriented to achieve certain results needed for survival ((Matte Blanco I. 1981).

However, the subsequent combination of the arbitrary distinctions of Ordinary Logic with the generalizations and the symmetrizations of Emotional Logic of the Unconscious System, makes it highly unlikely that there exist, between individuals, two representations perfectly identical of the same phenomenon and/or of the same process: When this happens, it is the result of chance or the result of a work of building consensus and uniformity of perception and representation of the phenomena and of the constructs, developed through Language. In turn the language, in order to be able to carry out such a function, must possess characteristics of constancy and invariance for all individuals who use it.

The Language is therefore a priority in the process of construction of cultures. This priority, already detected by Structuralist Model, cannot be, however, totally tyrannical: in linguistic production, in fact, the position of the subject is logically prior to its linguistic expression, then the language is, at least temporally, subseguent to the thought. On the contrary, from the point of view of the listener, the understanding of the position of the subject who speaks is subsequent to its linguistic expression, then the language precedes thought. The concept of objectivity therefore represents the referent of the consensus reached between speakers on a certain phenomenon, construct, and/or practice: its contents cannot be, therefore, never entirely stable, being subject to processes of continues redefinition originated by the difference between perception and subjective experience of the reality and the rules of construction of the information given by the linguistic tool: the perception and subjective experience thus represent an arbitrary excerpt of reality, while the language delimits the excerpt socially useful. The language, then, bases the social development of thought.

\subsection{The Limits of Logic}

The Ordinary Logic, including the Logic of Scientific Research, cannot explain everything because that everything cannot also contain the man that is explaining. In fact, in order to explain something, the man who explains must be outside/separated from the thing to explain, then cannot explain himself because it cannot be external to himself. This epistemological condition has enormous consequences, with regard to the dissemination of beliefs inherent in the sense of being in the world of the subject, and the meaning of relations that it maintains with the objects present in the world, since the subject acquires knowledge of objects through the operations that can perform on them, thus, not being able to perform operations on itself, cannot acquire (nor describe), in itself regard, the same type of knowledge that can acquire in respect of objects. That is to say that the experiences relating to this kind of knowledge, if had, must be either acquired that transmitted through different ways from those used for acquiring and disseminating knowledge about the world of the objects. For example, through the myth.

It is correct therefore to affirm that the myth is an attempt to build a discourse about the subject, that is impossible according to the Ordinary Logic. Consequently, this discourse can be ruled mainly by Emotional Logic, which knows no distinction between subject and object. Therefore, it will have the following characteristics:

(a) since the principle of symmetry does not allow to describe causal necessity, and can manifest itself only within relationships, the relational content to be transmitted through the communication will necessarily adopt the form of narration. In addition, since the Principle of Symmetry deals a relation as being identical to its inverse, will involve identification between the poles of the relation which is inscribed in the communication;

(b) since the Principle of Generalization does not describe the contents in a defined manner, these will be expressed through metaphors;

(c) since the Emotional Logic cannot pursue any purpose, will express itself through the Ordinary Logic;

(d) inasmuch as the productions referred to above are processed unconsciously/emotionally, they will also be perceived in the same way:

- since the Principle of Generalization operates on propositional functions that in one aspect express a general growing and in other retain some special characteristics of the individual thing from which are derived, it will assimilate experiences and functions performed by the personages of the narration to those lived and carried out normally from the listener

- since the Principle of Symmetry deals a relation as being identical to its opposite, the contents of the narrative will be perceived as referring to the listener and the characters of the story as expressions of features, parts or components of the same listener. The emotional mode of operation of the Unconscious System also lends itself to the production of representations of Divinity much better than Ordinary Logic. In fact (Carli R., 1987), it identifies the individual with the class of membership, attributing, to the highest degree, all potential included in the propositional function that defines the class. It also identifies the Deity with the same function because it does not know the individuals, but only classes. 


\subsection{The Institution as a System of Constance}

The regulatory parameter allowing both the permanence than the change of cultural models can be defined as a System of Constancy that regulates the Individual Constancies. Since it cannot exist apart from the individual acts and representations through which manifests itself in individuals, will be a function of the accommodation and/or the conscious adaptation, obtained through the Ordinary Logic, and unconscious, obtained through the Emotional Logic, of the Individual Constancies concerned, so as they saturate in individual interactions and relationships considered.

As regulatory parameter of individuals working in any social situation, and as a System of Constancy that regulates the Individual Constancies, it tends to counteract changes. For this reason, every significant social change must be preceded by moments of Chaos, caused by the crisis of the regulatory parameter underlying the social context before his change.

As a function of the accommodation and/or adaptation to the Individual Constancies, this parameter tends to develop Order (organization) from chaos. Both the chaos which precedes the change than the order that follows him, finally, cannot prescind from the contributions that individuals make to regulatory parameter. In their turn, both the chaos which precedes the change than the order that follows it, cannot prescind from the contents of the existing individual and collective Memories, even if they are not made explicit as such, since they represent the underlying constancy of every cognitive and emotional process.

The System of Constancy that regulates the Individual Constancies can therefore be considered the interface through which .. are produced, maintained and recovered both the memories than the conscious and unconscious collective identity. As produced by this System of Constance, the memory and the collective identity can never have a content of all stable and perfectly identical between individuals: its content is continually regenerated, rebuilt, adapted and modified by individuals in function of variables needs and situations, and its stability, in time, space and identity, continuously recreated in a manner both explicit and conscious than implicit and unconscious.

The System of Constancy that regulates the Individual Constancies therefore represents the interface through which the Collective Memory is built and reprocessed through the activities of the different speakers. It can therefore be stated that the myths, cults and rites are produced and edited mainly through the Emotional Logic, by mode that induce coherence and permanence of representations, actions and behavior in time and space, and by means of creative processes that are adjusted by the same System of Constancy that regulates the permanence and the change of the constancies relating to other cultural productions of collective interest.

This means that a story can become a myth in the condition of being compatible with the System of Constancy that regulates the Individual Constancies of the Community referenced. This compatibility may occur at two levels:

- at synchronic level, that is through the ability to express metaphorically stages and ontogenetic paths that allow the identification of individual listeners with the weft expressed by the narration

- at diachronic level, that is through the ability to provide listeners regulatory parameters able to allow an optimal adaptation to the environmental and psychosocial contexts in which they live.

To postulate a regulatory parameter that has the described above characteristics, may therefore explain both the permanence than the manner of the change in time and space of the cultural characteristics (and therefore of the identity of a group and/or a community), in a similar manner to the persistence of the individual identity on the basis of the permanence of the stability of the contexts within which it is located (Oyserman D., Elmore K., Smith G., 2012). Therefore the interpretation of a myth will be much more exhaustive the greater will be the number of its variants examined.

The same regulatory parameter, finally, can explain the co-occurrence of similar cultural characteristics in groups and/or community situated in different places, and who have not had the possibility of cultural exchanges: using both the Ordinary than Emotional Logic to satisfy the same needs, within similar environmental and psychosocial contexts, will be likely produced similar symbolizations. In the same way, it can explain the persistence, the diffusion and the variations of the myths in time and space.

\section{Methodology}

According to R. Barthes, every man and every people tells: the Narration is international, trans-historical and transcultural, and is present in myths and tales, legends, stories, tragedies and dramas, comedies, as well as in the paintings, films, newspapers and conversations. The Linguistics lends itself to provide a model with which to analyze the narrative, whatever their nature, however it stops to the sentence, which is constituted by different levels (phonetic and phonological, grammatical, contextual) that are in a relationship of hierarchical integration between them and that therefore cannot provide a meaning independently of the others.

In the same way, the Narrative consists in a hierarchy of levels you are in production and in use, both through the 
horizontal succession of words and phrases, than through the passage, vertical, from one level to another. In fact, the meaning of a narrative is not located at the end of same: rather it rides it. The Narrative can be analyzed within three levels: Functions, actions and discourse. A Function reveals its meaning only when integrates within a general line of action of an actor, and this action receives its significance in that .. is placed inside of a discourse that is produced through a specific code.

The function is a unit of content, what a statement means not the way with which it is built, which constitutes a Functional Unit. This can be constituted both by wider units (groups of phrases of varying length), than smaller of the sentence (terms and words), and can relate with other at the same level, or may assume their meaning only integrating at a higher level.

You can identify two large classes of Functional Units: the Distributional and Supplementary.

- The first refer to actions that open, maintain or close an alternate pattern of history, that is, that activate or solve a uncertainty. These units are Cardinals (or Nucleus) inside the story, and are both consecutive (which follow each other) that consequential (the existence of a unit makes it possible .. the materialisation of another), although the order of narration should not necessarily coincide systematically the two things. They are both necessary to the narrative than sufficient for themselves. The Cardinal Function can be identified only through its implications, then can be segmented through delays defined by sequences linked by a relationship of solidarity: the sequence opens when a term lacks an antecedent of the same type, and closes when another of its terms implies no further consequence. The sequence is always nameable and is always logically incomplete, because it is justified within the local context and rooted in the context of the wider narrative; moreover, it is understood as a self-contained, ready to act as a simple term for another sequence more wide.

- The second, supplementary at the first, comprise the indices or indicators descriptive of personality traits, feelings, atmosphere, philosophy, that help to decipher contexts and situations narrated, and are catalytic (Catalysis), or enter into a relationship with the Nuclei in chronological and parasitic manner, because they describe what separates two moments of narration. They interweave with the Nucleus an expansive relation, maintaining contact between the narrator and the listener.

In synthesis, it is not possible to delete a Nucleus of a narration without alter the same and it is not possible to erase a Catalysis without altering the Discourse (Barthes R., Duisit L., 1975).

The model offered by Barthes will be used to dismantle the myths in sequences which circumscribe Nucleus and identify Catalysis, in such a way as to make it possible, through Symmetrical Analysis (or Extraction of Asymmetry), the decoding in accordance with the Principles of Generalization and Symmetry, identifying the possible implications, and categorizing the same inside the evolutionary stage for which they seem most appropriate: decoding, in fact, may be articulated within the sequence of the evolutionary stages that Ken Wilber has recognized as characterizing human development in all areas of the planet.

This sequence, identified by comparing and contrasting both clinical models proposed by Western Psychology (Freud, Jung, Piaget, Arieti, Werner, etc.), than those contemplatives of different traditions rooted in different historical/geographical contexts of the planet (Zen Buddhism Mahayana, Vedanta, Sufi, Quabbalah, Christian Mysticism, Platonism, Aurobindo, etc.), identifies a universal development of personality, divided into ten stages (Wilber K., 1989a):

1) physical-sensory: the biological sphere, of feeling and perception, and derived sensorimotor knowledge. The needs are exclusively physiological, adjusted by a relationship with the environment of autistic/symbiotic type with premoral orientation

2) phantasmal-emotional: perceptions, sensations and feelings, emotions and sexual desires that give life to the simplest form of mental representation, image-based. The needs continue to be physiological, while the relationship with the environment is of impulsive type, oriented by desires

3) representational mind: structured in a manner basically narcissistic, at this stage the person is able to process symbolically the primary preoperative representations and, although it has overtaken the previous level, cannot easily assume its role. It emerges the need for security, parallel to the emergence of an awareness of the presence of risks and dangers that are present in the environment. The orientation toward the same then becomes impulsive/self-protective, with a behavior regulated by obedience consequent to punishment and an ingenuous hedonism

4) mind rule-role: the person can carry out operations and has a psychic structure able to assume the role of the preceding, and can perform with clarity tasks that require the observance of the rules, such as arithmetic operations, the inclusion in classes and hierarchical organization. It emerges the need of membership in respect of relational context and the environment, to which it is recognized the usefulness and the need, with conventional behaviors, conformist and 
adjusted by the approval of the persons important with which are woven and/or maintained relations (the rule 'by one-self' can be observed only beginning at this stage)

5) formal-reflective mind: the mind acquires the ability to think to think, then of introspection and self-reflection, which allows hypothetical-deductive and propositional reasoning, which allow to reach visions authentically pluralistic and universal. It emerges the need for self-esteem, conscientiousness and individualism, regulated by a post-conventionalism that recognizes both the law and order that individual rights

6) logical-imaginative mind: while at the preceding stage the mind is able to establish relations, at this is able to establish networks of mutual relations, then to build a vision of reality sudden and all-inclusive, in which integrate itself. We can say that at this stage the person has reached the highest degree of personal integration. It is thus clear the need for self-realization, which requires autonomy, integration and individual moral principles

7) mental: at this stage the person accesses the first level of the Trans-Personal Self, and begins to make a thin examination of cognitive and perceptive capacities of the mind, and thus begins to transcend them, obtaining visions of the world and of reality that go beyond any personal or individual interest

8) thin: This stage is considered the seat of acting archetypes, of Platonic form, shape-personal divinity. The perception and the mental representations which occur within this stage of development are perceived as illuminated and ecstatic

9) causal: at this stage the person acquires the awareness of the does not manifest source or transcendent foundation of each lower structure, an universal and without form-Self, common to all beings, wherein the centralizing attractiveness of the Ego passes in secondary order until to be completely abolished, leaving their place to a perception and sense of universal and without limits Self

10) last: crossed the previous stage, the conscience is revealed in its full integration and identity of the manifest form with the formless does not manifest.

Development through these stages is adjusted by the System of Self, which possesses the following characteristics (Wilber K., 1989a):

(a) identification: ability to distinguish between $\mathrm{I} / \mathrm{me}$ and $\mathrm{I} / \mathrm{non}-\mathrm{me}$

(b) organization: organizational function independent of external events, which tries to give mental unity and coherence

(c) will: capacity of free choice, accordant with the limits posed by the level of adaptation and development achieved

(d) defense: development and use of defense mechanisms having the function of maintaining the homeostasis of the psychical apparatus in function of the level of development achieved

(e) metabolism: factorization and metabolization of experiences, with the assignment of a role to the contents of the same in the building of the psychic structure

(f) driving: ability to cope pushed with different direction, choices relating to development and ascending or descending use of the structures described above.

The randomness of possible cultural productions, originated both from the arbitrariness of the distinctions made by the Ordinary Logic than the generalizations to infinity fruit of the Symmetric Logic, would therefore be reduced from the identity of the structure and functions of the System of the Self. The interaction between the identity of structure and functions and the historical and natural contexts, also regulates both the passage between one stage and the other, than the development of the specific cultural characteristics that these steps assume in time and space. The Ordinary Logic, finally, inside this model corresponds to the set of cognitive abilities spontaneously expressed by the neurophysiologic equipment of humankind, before being the object of the manuals of logic: the research models of Cognitive Sciences, in fact, assert that the human logical capacity arises as a revision of the innate ability of perception and movement, as expressed by our organism, which allow us to abstract concepts of temporal and spatial relations (as: above, below, inside, outside, through before, after, never, etc.), by actions undertaken on objects (such as: pull, push, scratching, cracking, split, etc.) or in space and in time (crossing, directing, finishing, beginning, while, etc.), or by the perceptive capacity, expressed by our senses, and the motor ability, expressed by our muscle/skeletal apparatus (Ekstrom S. R., 2004): even the paths of Ordinary Logic are rooted in an unconscious structure.

It is therefore not necessary to postulate that the persistence of a collective memory that is acquired through the repetition of the experiences of history and transmitted through the genetic code: indeed, it represents the fruit of psychic work daily reproduced and renovated to give a shape and a social function to the individuality of the psychic productions, in such a manner as to ensure continuity and coherence between the different representations, individual and collective, and constancy of social functioning even in the presence of a change of life contexts. It is not even necessary to assume diffusion phenomena, especially when they are not sufficiently tested by archeological and 
historical evidences, to explain the similarity between cultural productions of peoples living in different geographical, cultural and historical contexts (Note 1).

The model of evolutionary development of personality proposed by Wilber allows, unlike classical psychoanalysis, to treat the symbols in a more articulated mode, because:

- It recognizes different pathological conditions for each of the stages of development described (Wilber K., 1989b);

- It identifies mode of treatment for each of the diseases referred to in the previous point, also describing the different approaches to use, to interpret and treat the symptoms;

- It recognizes, in symptoms, a tendency to aggregate to the needs and potential present in various developmental stages, differentiating on the basis of the stadium, while preserving the layers of signification originated in the previous stages, which can be treated in a proper manner together with symptomatic expressions present in the stadium in which is located the patient in the treatment: this means that each symbol might have a different meaning, consistent with the stage within which manifests itself, have multiple meanings simultaneously, and change of significance in accordance with the evolutionary stage of membership of the person undergoing treatment (Wilber K., 1989c).

\subsection{Hypotheses}

Therefore, according Wilber's model, symbols can be interpreted in a manner consistent with the evolutionary stage within is located the person in analysis, while according to the Matte Blanco's model, they can be interpreted without necessarily refer to some mental pathology. In this way the application of interpretative psychoanalytic model, freed from constraint dictated by the clinical context, can prove that the generalizations and symmetrizations inside the myths contain the high adaptive value to put people in their own environment of reference within a Holistic Vision, able to adjust, through unconscious identification, both synchronously than diachronically the awareness of being subject to the laws of nature and rules of conduct effective in their socio-cultural context.

This model will be thus applied in the analysis of the myth of the origin of mankind according to Ancient Greek Mythology. The Myth will be analyzed through its variants more notes, which together can better give account of various facets that the same possesses, and how the same, also being designed in different spatio-temporal contexts, maintain a consistency and a overall continuity, able to provide a general framework sufficiently exhaustive both of the beliefs contained therein, than their adaptive value.

\subsection{Analysis and Interpretation of the Myth of Prometheus/Origin of Mankind}

To analyze a Greek myth involves the preliminary work of rebuilding of texts having different source for both location and historical context, than for culture and sensitivity of the author. However, since this stories had religious background, then referred to truth considered immutable, you can assume that the various authors who are striving in the production of texts had knowledge of the previous texts, and that have maintained with them a certain coherence. Although the Polytheistic Myths are structured around variations in time and space, it is however possible to dispose of careful research made by certain authors who have greatly simplified the work of collating and rebuilding of the Greek Myths (Graves R.,1955; Atsma A. J., 2000-2011), without for this refrain from paying attention to possible incompleteness and/or contradictions which might be an indication of lack of literary and/or archaeological material: the absence of organizations institutionally responsible to production and collection of sacred texts which marked the religiosity of Greek culture (Vernant J.P., 1987), in fact, if on the one hand has allowed the proliferation and the enrichment of the stories, on the other hand has made fragmentary their availability. Drawing from the meticulous work of rebuilding done by other scholars, were then selected sections of stories from different authors, consisting of Narrative Nucleus and/or Catalysis, which in various ways have helped to describe a myth that, while presenting different facets, can be traced back to a single and consistent image. 
Table 1. Symmetrical Analysis of the Myth of Prometheus/ the Origin of Mankind

\begin{tabular}{|c|c|c|}
\hline \multicolumn{3}{|c|}{ THE MYTH OF PROMETHEUS } \\
\hline SOURCE & NUCLEUS/CATALYSIS & $\begin{array}{c}\text { SYMMETRICAL } \\
\text { ANALYSIS/ESTRACTION OF } \\
\text { ASYMMETRY }\end{array}$ \\
\hline $\begin{array}{l}\text { Prelude } \\
\text { Aeschylus, } \\
\text { VI-V sec. B.C. } \\
\text { (Romagnoli) }\end{array}$ & $\begin{array}{l}\text { The Titans do not listen to the indications of } \\
\text { Prometheus who exhorted them to use the } \\
\text { astuteness in the fight against Zeus, then } \\
\text { Prometheus decides to protect his mother Gea and } \\
\text { to help Zeus (nucleus/catalysis). }\end{array}$ & $\begin{array}{l}\text { There is no symmetrical } \\
\text { overturning between Prometheus } \\
\text { and the Titans, its similars (Stage } \\
\text { 4): The Titans have no strategy or } \\
\text { critical thinking skills, that the } \\
\text { forethought of Prometheus has. The } \\
\text { frustrated need for belonging of } \\
\text { Prometheus strengthens its ties with } \\
\text { the mother Gea, who is protected } \\
\text { (stage 5; principle } \\
\text { generalization). }\end{array}$ \\
\hline
\end{tabular}

1. Hesiod, The Gods created more races of mortal men, before VII-VI sec. B.C. that it belongs to the narrator:

(Sanasi/a) $\quad \mathbf{1 . 1}$ The first, said golden, never get old, remained young and strong until death, which came in sleep. The earth gave them every good, the work was not necessary (nucleus).

Aeschylus, (Valgimigli)

Hesiod

(Sanasi/a)

Aeschylus, (Valgimigli)

Hesiod

(Sanasi/a)

Aeschylus, (Valgimigli)

Hesiod (Sanasi/a)

Aeschylus, (Valgimigli)

Hesiod

(Sanasi/a)
Men use the fire, present for divine gift.

1.2 The second, said silvered, enjoyed a centenary childhood, but to limit of youth came to death because of his own foolishness, because it was unable to control his violence nor wanted to venerate the gods. This generation is reproduced by coupling with the nymphs Meliai, giving origin to the lineage of bronze (nucleus).

Division of the ox, denial of the fire by Zeus.

1.3 The third, said bronzed, was powerful and terrible, equipped with invincible force and devoted to pain and violence. This race destroyed herself with their own hands (nucleus).

Theft of fire, the apparition of Pandora, chaining of Prometheus

1.4 The fourth was heroic, fairer and better, and perished because of wars, battles and marine disasters, for then living on the Island of the Blessed at the behest of Zeus, where it now lives happily as lineage of demigods, enjoying a generous land that gives them three harvests per year (nucleus/catalysis).

Pacification between Zeus and Men, liberation of Prometheus.

1.5 The fifth is the race to which belongs the narrator.
The condition in which each need is automatically satisfied (Stage 1), do not persist (Gen).

Dwell too much on the delights of childhood (Stage 2) does not allow you to develop the capacity for adaptation/accommodation (Gen). The foolishness of the lineage of silver, coupled to the divinity of the Meliai Nymphs, produces uncontrolled power (Gen).

Brute force (whose fullness is reached in the youth), alone, is not suitable for the survival (stage 2-3), because it leads to destruction (Gen).

The right life is regulated (stage 4-5) from ideals (Gen). 
2. Sappho, VI Prometheus creates man modeling a statue of clay, sec. B.C.;

Aesop, VI sec.

B.C.; Ovid, I sec. B.C.- I sec.

A.D.; Iginus, I sec. B.C.;

Apollodorus, I

sec. A.D.;

Pseudo-Iginus,

II sec. A.D.

(Atsma A. J.,

2000-2011;

Prometheus;

Pronoia)

3. Socrates, 469-399 B.C.

(Sanasi/c) which took life through a divine breath (of the same Prometheus, Zeus or Athena, depending on the version). Athena was closely identified with Pronoia, wife of Prometheus and the Goddess of the prediction (nucleus/catalysis).
The clay is a natural and inanimate material, while the breath belongs to the living things: Man is composed of natural elements, inanimate, animated by intangible elements (Gen).

\author{
3.1 The Gods forged the mortal races inside the \\ earth, mixing earth, fire and other substances that \\ merge with them (core).
}

3.2 The gods gave to Prometheus and Epimetheus the mandated to provide every race of the faculty to them adequate (nucleus/catalysis).

3.3 Epimetheus takes on the burden of carrying out this work, and assigned to each race the capabilities necessary to survival, leaving the human barefooted, naked and defenseless because, forgetting it, had assigned all the faculty to other races (nucleus).
The Mortal races are born from a mixture of natural elements by the Divinity (Gen). The blend of natural elements (Stage 5), generates the divinity (principle of symmetry).

The human mortal races are characterized (Stage 5) by Forethought -Prometheus- and by Afterthought -Epimetheus-(Gen.).

The Afterthought (Stage 5), for mankind, does not guarantee the survival (Gen.).
4. Aeschylus, (Romagnoli)
4.1 Men lived like ants, dwelling underground, incapable of distinguishing the seasons (nucleus).

4.2 Prometheus alleviated the pains of men who, confusing everything, saw without seeing and heard without hearing, making them masters of their own minds, instruct them the art of divination, numbers and writing, which allows you to conserve memory, and all the arts (nucleus).

\begin{tabular}{lll}
\hline 5. Hesiod & 5.1 Having to organize a feast among men and gods, The Forethought serves and \\
(Sanasi/b) & Prometheus divided an ox so as to reserve to the protects the weakest, without caring \\
men the pulp and the entrails, hidden under the skin about the strongest (stage 4-5), \\
of the animal, and to Zeus the bones stripped the which do not need protection \\
flesh off, wrapped of grease concealed from the (Gen.). \\
peritoneum (nucleus/catalysis). \\
5.2 Zeus realizes the deception and meditates Prometheus deceives Zeus, and \\
revenge, then chooses the bones. From here the Zeus deceives Prometheus (Symm). \\
custom of burning the bones of animals to honor To use the deception in relationship \\
gods. Zeus obtains revenge on denying the fire to (Stage 5) entails negative
\end{tabular}




\begin{tabular}{|c|c|c|}
\hline & men (nucleus). & consequences (Gen) \\
\hline $\begin{array}{l}\text { 6. Socrates } \\
\text { (Sanasi/c) }\end{array}$ & $\begin{array}{l}\text { Prometheus robs the art of Hephaestus and the } \\
\text { wisdom of Athena, giving them to men, and also } \\
\text { steals the fire, because without it men would not } \\
\text { have been able to use the gifts. The men had then } \\
\text { tools to survive and prosper, but lacked them politic } \\
\text { wisdom, held by Zeus, that could not be stolen from } \\
\text { Prometheus, why had not access to the Acropolis } \\
\text { because of the terrible guards of Zeus (nucleus). }\end{array}$ & $\begin{array}{l}\text { Man acquires the ability to survive } \\
\text { (Stage 5) through the Forethought. } \\
\text { This capacity emerges as a breach } \\
\text { (theft) from the divine/natural order. } \\
\text { However, Forethought is not the } \\
\text { ability of self-government (Gen.). }\end{array}$ \\
\hline $\begin{array}{l}\text { 7. Socrates } \\
\text { (Sanasi/c) }\end{array}$ & $\begin{array}{l}\text { 7.1 Although possessing the instruments suitable for } \\
\text { the survival, men were wrongs with one another, } \\
\text { consequently failed to form alliances to fight the } \\
\text { war against the fairs, toward which succumbed } \\
\text { (nucleus). } \\
\text { 7.2 Zeus feared that the human race would } \\
\text { extinguish, then sent Hermes among men, for giving } \\
\text { them Justice and Respect (nucleus/catalysis). }\end{array}$ & $\begin{array}{l}\text { The technology may not base the } \\
\text { self government (Stage 3) of } \\
\text { Mankind (Gen.). } \\
\text { Justice and Respect make possible } \\
\text { the coexistence and collaboration } \\
\text { (Stage 5) among men (Gen.). }\end{array}$ \\
\hline
\end{tabular}
\begin{tabular}{ll}
\hline 8. Aeschylus, & Prometheus steals the source of fire, concealing it \\
(Romagnoli) & inside a ferrule (nucleus).
\end{tabular}
The Forethought surmounts the adverse situations using the laws of Natural Order (Stage 5); in this way, however, violates his belonging to the same order: The theft, in fact, do not pertain so much the fire, as the ability to control it, expressed by its containment in the ferrule (Gen).

9. Hesiod Zeus notices the theft and commands to Hephaestus (Sanasi/b) to forge a woman from the mud. This woman was dressed and embellished by both Hephaestus than by Athena and donated to Men (nucleus).

10. Hesiod 10.1 Pandora received as a gift from the Gods the (Sanasi/b) beauty, the spirit, the grace, the arts, the ability to lie, to make misleading speeches and adopt subtle strategies, in addition to a vessel closed with a lid. By this woman, Pandora, derives the feminine human race, source of damage for men even if you avoid the wedding, since you die alone, leaving a distant relatives your belongings (nucleus/catalysis). Even if you marry a woman chaste and with prudent mind, you will need to balance good and evil in time (nucleus/catalysis).

Hesiod (Sanasi/a)
10.2 knowing the revengeful intentions of Zeus, Prometheus warns Epimetheus to accept not any gift from Zeus, but Epimetheus did not pose the mind to the indication of the brother and accepted the gift of Zeus (nucleus/catalysis).

10.3 Pandora take off the lid from the vessel, dispersing in the world the evils ..., closing it before it was dispersed also Hope (nucleus).
The abandonment of the natural order (stage 4-5) involves uncontrollable changes (Gen.).

To surrender to the attraction of beauty, grace and of the arts; to succumb to falsehood, to misleading speeches and subtle strategies (Step 4), entails the risk of incurring unknown outcomes (Gen).

To make choices more reasoned does not guarantee better outcomes: what seems right, convenient, pleasant and positive in a given time may not be (Stage 6) subsequently (Gen.).

The symmetric inversion between Prometheus and Epimetheus does not occur. The Forethought cannot regulate (Stage 6) the Afterthought (Gen.).

The Afterthought obtain the awareness which is inherent in the Forethought, after having 
succumbed to the attraction, falsehood, misleading speeches and subtle strategies (Stage 6). The Hope makes possible the ability to adjust according to the Forethought even to those who acts in accordance with the Afterthought (Gen).

11. Aeschylus, The gifts of Prometheus resulted only blind hopes, (Romagnoli) although they have produced great benefits for men allowing the cure of diseases, divination and all the arts, because art is weaker than the necessity to which even Zeus will succumb (nucleus/catalysis).
The Forethought improves life, however the pain and the evils are inevitable (Gen). The Forethought cannot change (Stage 6) the causal laws (Gen.).
12. Aeschylus, (Romagnoli)
12.1 Zeus enchained Prometheus to a pillar in the place where an eagle devoured his liver during the day. The liver grow again at night to be devoured again the next day. Kratos and Bia fulfill the task ordered by Zeus to immobilize Prometheus, while Hephaestus enchain him with inseparable bonds (nucleus).

12.2 The job is done reluctantly, because of the parental relationship that links the three to Prometheus, since they cannot disobey to an order of Zeus: "Only Zeus is free," says Kratos (nucleus/catalysis).

12.3 Poseidon visits Prometheus, sorry for the relationship and the estimate that nourishes in his regard, and resolves to intercede to Zeus in his regard, recommending Prometheus of containing in the language (catalysis).

\section{Aeschylus, (Romagnoli)}

\section{The absence of ability to self-government involves the deprivation of freedom to Titan (Stage 5), which entails the Forethought being transformed into a painful desperation and rumination (Gen.): the liver, in fact, was considered to be the seat of the reflective intellect (Sanasi/d).}

Freedom is inherent (Stage 5) to political wisdom (Gen).

The identification inside the parental relationship (Sym), represents a tool of mediation between the suffering of Prometheus and the political power of Zeus (Gen). Freedom is a function of the relations with the political power, which are regulated through language (Stage 4). For the Forethought of a Titan, adjust its own language is a condition of access to political relations kept in a condition of freedom (Gen).

From delirium may arise (Stage 7) great changes (Gen).

The Political power creates conditions (Stage 7) for his same decline (Gen). 
14. Aeschylus, Hermes becomes the spokesperson of the order of (Romagnoli) Zeus to reveal the wedding that will cause its decline. Prometheus refuses, not accepting a servile and submissive role, as that shown by his interlocutor, despite Hermes unfolds him the terrible consequences of his decision (catalysis).
There is no freedom in servile roles (Stage 6), even if they present advantageous aspects (Gen). There is no symmetrical reversal between Prometheus and Hermes.
15. Aeschylus, (Romagnoli)
Gaea, mother of Prometheus, offers to intermediary with Zeus, proposing the liberation of Prometheus in exchange of the revelation of prophecy, note to Prometheus, which would have allowed Zeus to avoid its decline. Prometheus accepts (catalysis).
Mediation can alleviate the suffering caused by the conflict between Forethought, desire of freedom and lack of skills (stage 4-5) necessary to satisfy this desire (Gen). The political negotiation can be a source of freedom (Gen).

\begin{tabular}{ll}
\hline 16. Aeschylus, & Comes, with the consent of Zeus, Hercules, which \\
(Romagnoli) & $\begin{array}{l}\text { kills the eagle that haunts Prometheus, which thanks } \\
\text { (nucleus). }\end{array}$
\end{tabular}

17. Aeschylus,

17.1 Comes Hermes that announces the acceptance (Romagnoli) of the Gaea's proposal by Zeus. Prometheus reveals the prophecy and Hercules breaks the chain that imprisoned Prometheus (nucleus).

17.2 Hercules offers Chiron to Zeus, because he asks to die, incurably wounded by a poisoned arrow launched by Hercules by mistake. Chiron digs into the tartar (nucleus).

17.3 Prometheus surrounds him head with a crown of wicker, as a sign of submission (nucleus).

The suffering caused by the conflict (Stage 4) between the Titanic Nature, incapable of self-government, and Forethought, terminates (Gen.)

The Political Power free Forethought by suffering, and Forethought free Political Power from the conditions of its decline (Symm). An heroic act frees the Forethought (Stage 6) from suffering (Gen).

The human/animal dual nature is relegated in the Unconscious (Stage 6).

The freedom of the wild nature, rebellious, evil, characterized by masculine aggressiveness and violent and unlimited insolence, proper to the Titan, is dependent on the ability of self-government (Gen), and must be subject to the Social Order, even if capable of Forethought (Stage 6)

18. Ovid, I sec. The Arcadian King Lycaon tries to serve human B.C. (Atsma flesh to Zeus, that destroys his house and convenes The impiety is not suitable (Stage 6) to the survival of Mankind (Gen).
A. J., a divine counsel in which announces its decision to 2000-2011; destroy the lineage of bronzed race with a great Deukalion \& deluge (nucleus).

Pyrra)

\begin{tabular}{|c|c|c|}
\hline $\begin{array}{l}\text { 19. Apollodorus, } \\
\text { I sec. A.D. } \\
\text { (Atsma A. J., } \\
\text { 2000-2011; } \\
\text { Deukalion \& } \\
\text { Pyrra) }\end{array}$ & $\begin{array}{l}\text { Prometheus warns his son Deukalion (had from } \\
\text { Pronoia), who had married Pyrra (daughter of } \\
\text { Epimetheus and Pandora), to build an ark, charge it } \\
\text { with supplies and embarking (nucleus). }\end{array}$ & $\begin{array}{l}\text { The Forethought prevents the } \\
\text { extinction (Stage 6) of Mankind } \\
\text { (Gen). }\end{array}$ \\
\hline $\begin{array}{l}\text { 20. Ovid, } \\
\text { Apollodorus }\end{array}$ & $\begin{array}{l}\text { urviving at Deluge (together } \\
\text { ke refuge on the mountain }\end{array}$ & $\begin{array}{l}\text { Purified from his wickedness, the } \\
\text { numan race is reborn heroic (Stage }\end{array}$ \\
\hline
\end{tabular}


(Atsma A. J., 2000-2011; Deukalion \& Pyrra) version), Deukalion and Pyrra throw, advised by Hermes or Themis (depending on the version), behind them some pebbles (the "bones of your Great Mother", according to the oracular indication): the pebbles thrown by Deukalion generate men, while those thrown by Pyrra generate women. The earth spontaneously produces animals and vegetation (nucleus).
5), although always originated from

Forethought/Deukalion and Afterthought/Pyrra (Gen).

\subsection{Discussion of the interpretations of the Myth of Prometheus}

The myth of Prometheus was interpreted according to different points of view: some attach to it an emphasis on the ethics of progress (Kohl M., 1985), also highlighting its destructive potential (Small B. Jollands, N., 2005). To similar conclusions reached, after discussing the evolution of key psycho-analytic interpretations, Orfanos: starting from S. Freud, according to which the ferrule within which Prometheus had hidden the fire represents a phallic element and the punishment of Zeus the revenge for the theft of his own phallus, subsequent developments of psychoanalysis have proposed, with Spitz, that the punishment of Zeus represents, instead, a manifestation of the envy of the same toward the creativity of Prometheus and, with Rank, the inhibition of the tendency of the personality to create itself, i.e. the inhibition of self-determination. Orfanos concludes its examination by saying that the myth of Prometheus represents both the ethics of the industrialization, the triumph of the material comfort and of a life less painful, than that of creativity, of perseverance in the search for solutions even in a desperate situation, expressed by hope hidden in the bottom of Pandora's vessel, then the ethics of civilization and emancipation (Orfanos S. D., 2006). This evolution of the psycho-analytic interpretations have in common the ruling out of the centrality of the oedipean conflict by the content of the myths, which are therefore interpreted in the light of different models (such as the relational .. and/or analysis of the Ego models).

However, these innovative interpretation cannot explain the way through which a narration which expresses interpersonal (according to interpretation of Spitz) or intrapsychic conflicts (according to interpretation of Rank) can, like the oedipean one (according to interpretation of Freud) attract the interest of whole communities for hundreds of years: at the bottom, the three interpretations proposed concern intimate affairs of interest to a single person, that not always can be identified with those of a Community. Furthermore, although Orfanos also considers the Pandora's vessel and has proposed that the myth represents the ethics of emancipation and civilization, has, as Freud, Spitz and Rank, omitted to evaluate several characters, situations and details of narration, reducing a lot of the flow rate of the Myth: the Myth of Prometheus, in fact, includes many other characters and situations, and cannot be reduced to episodes of theft of fire and the punishment suffered for this act (see table 1: Prelude and lines: 1-4, 7, 11, 12.2-.3, 14-20)

Unlike .. psychoanalytic .., the Bereford's historical/philosophical approach interprets the myth considering the figure of Protagoras, the agnostic philosopher who had proposed, through the myth reported in Socratic dialog, a theory of the natural origin of human characteristics through an allegory that would protect by the dangers caused by political tendencies which attributed to agnostics the guilt to deviate the young generations from the behavior considered morally correct. According to this allegory, Epimetheus, Prometheus and Zeus would represent the innate tendencies of men: to learn from the mistakes (Epimetheus), to produce works of intellect (Prometheus), and build and maintain (Zeus) social relations (Bereford A., 2010). The author, however, does not evaluate with the necessary attention the reasons for which the central characters of the Myth are Titans and not Olympic divinity, which appear as victims of theft (Zeus, Athena and Hephaestus) or as donors of gifts and dispensers of punishments (Zeus): the allegory, in fact, could well operate equally if the fire, the art and the wisdom had been donated to the men from the Gods (respectively by Zeus, Athena and Hephaestus), as happened for justice and respect (that in the myth narrated by Protagoras are donated by Zeus), instead of robbed by Prometheus. The relationship between men, Titans and Olympic Divinity, as well as the theft of fire and the punishment of Prometheus, therefore remains excluded from the allegorical interpretation proposed, despite being an essential component of the Myth.

These elements are central to the interpretation proposed by Kerény, according to which they would represent the unchanging existential condition of man, whose creative and imaginative efforts, made to allow survival, are also a source of deprivation (imprisonment) and suffering (torture inflicted by the eagle that is nourished by the liver of Prometheus). The author, however, also highlights a possible alternative epilogue to this pessimistic conclusion, assuming that the wound of Prometheus can be healed, after his liberation, spontaneously or with the intervention of the centaur Chiron, mentioning also to a Italic variant of the myth, which concludes with the liberation of Prometheus by, in addition to Hercules, Athena and Asclepius: according to this version, then, the condition of suffering caused by 
existence could be alleviated, cured and exceeded (Aclepius is in fact a medical divinity able to heal the wounds caused by the eagle). However, according to the interpretation of Kerény, this condition cannot be deleted: in fact, Chiron, suffering from an incurable wound, is offered to Zeus in exchange of the release of Prometheus. Unfortunately, in addition to a representation of the scene in which Prometheus is freed from the bonds, there are no other details that can support this conclusion of the Italic version, and also are not available further details relating to the liberation of Prometheus also in the Greek version (of the special drama of Aeschylus, Prometheus freed, in fact, remained only a few fragments). The Italic version is portrayed on some mirrors in which Prometheus is shown together with Hercules and Apollo; Hercules and Castores; Hercules, Asclepius and Athena, then these representations relate to the likely involvement of those personages in the story, which does not exist in that of Hesiod, Protagoras and Aeschylus. Unfortunately there are no more testimonials that can describe in detail the Italic myth, unlike ..... the Greek .. . Kerény, finally, emphasizes the similarity and contrast between Prometheus and Christian Redeemer, very evident in italic depictions of a Prometheus crucifix, which refer to a Prometheus Redeemer and in need of redemption at the same time: The Redeemer for mankind, toward which was donor of gifts, and in need of redemption for the divinity, toward which was the protagonist of irreverent theft (Kerény K., 1977).

According instead to the interpretation described in table, the liberation of Prometheus comes through an heroic act, which involves (or is defined by) the integration of political power with the ability to forethought, symbolized by the exchange between Zeus and Prometheus, from which everyone receives liberation: the first by the conditions of its decline, created by his own behavior, and the latter by the painful rumination, created by his desire of freedom left unfulfilled because of its Titanic inability of self-government, which restrains its ability to forecast (line 17.1). Therefore, although the elements relating to the conclusion of the myth of Prometheus should remain fragmented, a wider interpretation may however be attempted by considering the various versions of the Myth, and placing the same within its horizon of mythical reference: in this way the myth would extend also to the origin of mankind and his adventure in the world, and could be considered as a description of the evolutionary path of man within its life cycle.

In this regard, it is enlightening the reading proposed by Vernant for the dividing of the ox, wherein the bones, since remain after the death, symbolize immortality, while meat, destined to putrefaction, death and the need to be nourished: according to this interpretation, then, Zeus receives from the Prometheus's sharing the symbol of immortality, divine characteristic, therefore his resentment for the part of the ox obtained would be facade. Vernant, moreover, focuses on the figure of Pandora, which represents a mediator element between the animality and Divinity: on the one hand, in fact, she needs to be nourished and introduces the birth through impregnation, gestation and parturition; on the other hand, as the bearer of Elpis (according to Plato waiting for an event, which denotes hope, if the event is pleased, and fear, if the event is ominous), marks the separation from both the animal than the divine world, since these worlds are insensitive to Elpis: the first for unawareness of good, evil and death, and the latter for indifference, as a place of immortality, on these issues (Vernant J. P., 2006). The author, however, ascribes to Elpis, then to Pandora, the promethean side of man, therefore excludes that Prometheus and Epimetheus may represent man equally. Similarly, contrary to what was proposed by Bereford, recognizes human characteristics only in Pandora, therefore the meaning of the other personages remains unclear in his interpretation. Greater clarification could therefore obtained recognizing human characteristics (i.e., psychic functions) in all the personages: in this way, the mythical narration would represent the scene within which acting functions and psychic dynamic, regardless of various personages that embody them. For what concerns the myth of Prometheus, on the other hand, the identification between Titans and Mankind is already clearly expressed in the parallel between the prelude and the line 6.1 of Table 1, wherein the Titans and Mankind will be badly affected by the same inability to perform actions of common interest, coordinating efforts. Therefore, recognizing the human characteristics in all the personages of the Myth, the Titanic side (more that Promethean) of man would already be present both in Prometheus, because he is capable of acting on the basis of a predetermined pattern, than in Epimetheus, who is characterized by the acting without the same. In fact, the Epimethean Aftertought does not identify itself as much with the absence of forecasting capacities and/or with the aptitude to learn from the mistakes (as deemed by Bereford), as the arrangement to act spontaneously and to learn from the experience (see line 3 of table 1), apart from the successes and failures obtained through such spontaneity, not mediated by the ability to predict: Epimetheus then lives the moment, rather than being a naive or stupid. Therefore Pandora, as the bearer of Elpis, more that a damage, represents a gift made by Zeus to the Epimethean component of Mankind, which allows you to learn from the experience without to renounce to spontaneity: in fact, on the one hand Prometheus offers gifts that allow men to alleviate the evils that humanity suffers (in myth escapees from Pandora's vessel), and on the other is a prisoner of his inability to self-government (Zeus, in fact, in the Myth represents both the social and political order - as a donor of justice and respect- than the natural ordering - inasmuch as it imposes the penalty to the Promethean knowledge of the laws of nature- , that are qualities both absent in the Titans) and, consequently, suffering because his ability to predict cannot to be used because of his imprisonment: the liver, who is torn from Eagle send by Zeus, is in fact the seat, according to the Greek Conception, of the Reflective Intellect (Sanasi/d). 
A reading more extended, moreover, could also protect from possible misunderstandings, which is the one in which it is incurred Vernant, when he says that, before Pandora, did not exist the evils (do not seen and do not feel), freed from her vessel, because Golden Race knew not evil (Vernant J. P., 2006): in fact, the events of the theft of fire and the apparition of Pandora are held during the Bronzed Age, and not in that of the golden, as erroneously considered by Vernant; moreover also the golden and the silvered races are mortal and suffering from the evils of whom do not have awareness (see line1. of the Table1). The gesture of Pandora, therefore, carries the evils to the awareness of Epimetheus, rather than to disseminate them, and it is complementary to the gifts donated from Prometheus to Mankind (lines 6 and 11 of the table), as well as complementary are the characteristics of Prometheus and Epimetheus. Moreover, Vernant attaches to Pandora the status of first woman by failing to grasp some nuances that dilute her role of progenitor: the Bronzed race was born by the coupling between the Silvered race and the Meliai (line 1 of table) and is destroyed (except some survivors, depending on the version - line 20 of table) from deluge wanted by Zeus (Apollodorus), while the heroic lineage originates from the gesture of Deukalyon and Pyrra, respectively the sons of Prometheus and Pronoia, and Epimetheus and Pandora, which produces the new human race from the bones of the Great Mother: Pandora is, then, the progenitor of the first woman (together with Epimetheus) as Prometheus (together with Pronoia) is the progenitor of the first man. This first pair also comprises the woman (Pyrra), resulting from the intersection between the characteristics of Epimetheus and those of Pandora, and the man, resulting from the intersection of the characteristics of Prometheus and Pronoia. The couple thus composed comprises then Titanic characteristics, derived from Prometheus, Epimetheus and Pronoia, and Divine, derived from Pandora, since invention of the Gods. The human race that follows, moreover, from the transmission of these characteristics in the bones of the Great Mother and therefore in the Heart, that at the end generates other males and other females, which complement the other men (of the lineage of bronze) survived to the deluge: the human sexual reproduction, therefore, comes after the Great Deluge, and affects men and women born from the seeding of bones/stones in the ground, rather than from the formation through clay and Divine Breath; human characteristics, therefore, are explained through a genealogy rather complex, which includes both Divine and Titanic than human elements and material resources. According to the epilogue of the Myth, then, Pandora not directly generates the human race, which in the end is produced by multiple progeny. In this way, through the myth of Prometheus, in all the variants considered, the Greek culture has explained the origin of the many facets of human characteristics (including the unconscious bliss of the golden race, the foolishness of the silvered race, and the stupid arrogance of the bronzed race, unfortunately still recognizable in many personality traits of relatives, friends, acquaintances and people commonly encountered on the road, in addition to historical events past and current), without infringing the prohibition of incest.

\section{Conclusion}

The myth of Prometheus, in the light of the proposed interpretation, represents the becoming of Man, as it unwinds from birth to death (mortals races described by Hesiod, in fact, represent the evolutionary stages of infancy (golden race), childhood (silvered race), youth (bronzed race), maturity (heroic race). The interpretative model used allows, moreover, to explain the choice to use Titanic and Olympic Divinity to represent human characteristics, and the dynamics within which they interconnect and evolve. The Post-Freudian Psychoanalysis decodes better these dynamics.

In fact, Prometheus and Epimetheus are Titans, i.e. wild divinity, rebels, evil, characterized by masculine aggressiveness and violent and unlimited insolence (Kerény K., 1997), defeats from Olympic Divinity after a war lasted ten years (Sanasi/b).

The aggressiveness has been examined in accordance with an evolutionary viewpoint, analyzing the dynamics that bind the infant to the mother. According to this model, the aggressiveness is manifested in the newborn in the presence of a poor capacity to tolerate frustration arising from the failed fulfillment of his need/desire of breast: when the newborn search the breast and this does not appear immediately to fulfill his need, conceives this absence as a "bad breast", which becomes the object of imagined aggression; if the ability to tolerate frustration related to this absence is good, the newborn manages to conceive the absence as a "non-breast", and in this case will born a thought; otherwise, being the breast a single one, is forced to split himself and split the same breast in order to be able to defend the "good breast" by its own attacks, projecting the "bad breast", together with him own related aggressive components, outside: in this way, however, the aggressiveness projected appears as a component of the object on which the same was projected, then it is acted and suffered at the same time, in a phantasmal manner. In optimal conditions the mother contains the frustrations of the newborn and returns, mitigated, the persecutory fantasies of the newborn, which can re-internalize them and recompose the integrity of breast and, together, of itself. In this way the child recognizes that the bad breast, that does not nurture, is the same good breast that does, so it can recognize the motiveless of his aggressiveness and access the depressive position. This position is characterized by the admission of own guilt, the gratitude toward the external objects and the presence of repair actions against breast damaged by own phantasmal attacks. Otherwise, the child remains in the paranoid position, which is characterized by an inability to integrate the splitted and projected parts and 
to recognize the entire object, the breast (or any other object), and maintain with it a healthy relationship, characterized by gratitude, convivial exchanges, trust, and the recognition of guilt and error (Bion W. R., 1970; 1972).

The paranoid and depressive positions can affect healthy people for all life. The first is defined, according to this model, by dynamic of splitting and projection which may originate in any context in which it is present a desire/need dissatisfied and a corresponding inability to tolerate frustration and generate thoughts, then can affect whatever component of the personality that is not sufficiently formed and mature to recognize it limits and defects, together to the merits ... of the people with which it is in relation: the fight and the dialectic between Olympic and Titanic Divinity would be, then, the oscillation between the paranoid and depressive position, namely the maturative and formative process that marks the passage from mode of primitive and asocial mental functioning, to .. mode of operation adult and socially arranged.

Inside this oscillation is therefore also the desire for freedom, which can be achieved when social relations and interpersonal relationships are not affected by the paranoid position, which makes the same intolerable, as a source of frustration. A life bereaved of social and interpersonal relations, on the other hand, would be equally intolerable and unacceptable because it would drastically reduce the chance of survival and realization of individual, leading inevitably to the extinction of the same human race. On the whole, considered in all its variants, the Greek myth of the origin of man, as expressed by the myth of Prometheus, expresses vicissitudes expressed by psychic abilities present in the Development Stages 1-7, with a prevalence of the stages 4, 5 and 6.

As a conclusion, then, we can say that the myth of Prometheus narrates even fatigue which man must support in order to be able to dispose of his freedom: a fable of Aesop (VI century B.C., fairy tale 535), in fact, tells that once Zeus commanded Prometheus to illustrate men the way of freedom and slavery. Prometheus built the path of freedom lasts at the beginning, impracticable and steep, without drinking water from nowhere, full of thorns and full of dangers from every part. In the end, however, it becomes a smooth plane delimited by paths and full of woods, fruit trees and water courses. Then the stressful experience ends in rest, for those who breathe the air of freedom. The track of slavery, instead, begins as a smooth plateau, full of flowers, enjoyable to watch and lush, but in the end it becomes impracticable, steep and insurmountable from all sides (Atsma 2000-2011; Prometheus).

It can also be stated in general that the Greek Mythology explicitly states, although unconsciously, a symmetric inversion between the creation of mankind by the Gods and vice versa: in fact, consistently with what reported in line 3 of table 1, this symmetrical overturning is explicit in the Theogeny of Hesiod, in which it is described the primary emersion, from the Chaos, of the Earth, of Tartar and Eros, from which will generate all the divinity that characterize the Greek Mythology. The myth of Prometheus, with the creation of man from mud by part of Divinity (Titanic and/or Olympic), then completes the relation: Chaos, Earth, Tartar, Eros, Titanic and Olympic Divinity, Mankind, are joined by identical roots: Chaos, that is the condition that comes before the born of the experience. The Greek theology, therefore, is basically laic.

\section{References}

Apel, K. O. (1977). L'Apriori della Comunità della Comunicazione e i Fondamenti dell'Etica. Il Problema d'una fondazione razionale dell'etica nell'epoca della Scienza. In: Comunità e Comunicazione. Torino, Rosemberg \& Sellier

Apollodoro. Biblioteca. http://www.sunelweb.net/modules/freecontent/index.php?id=594

Atsma, A. J. (2000-2011). DEUKALION \& PYRRA: http://www.theoi.com/Heros/Deukalion.html

Atsma, A. J., \& Atsma, A. J. (2000-2011). PROMETHEUS. http://www.theoi.com/Titan/TitanPrometheus.html

Atsma, A. J. (2000-2011). PRONOIA. http://www.theoi.com/Nymphe/NymphePronoia.html

Barthes, R., \& Duisit, L. (1975). An Introduction to the Structural Analysis of Narrative. New Literary History, 6(2), On Narrative and Narratives (Winter, 1975). http://dx.doi.org/10.2307/468419

Bateson, G., (1963). It. Trad.; Il Ruolo del Cambiamento Somatico nell'Evoluzione. In: Verso un'Ecologia della Mente. Milano, Adelphi.

Bereford, A. (2010). The Story in the Protagoras: Sketching a Naturalistic Ethics. http://www.faculty.umb.edu/adam_beresford/research/story_in_protagoras.pdf

Bion, W. R. (1970). Analisi degli schizofrenici e metodo psicoanalitico, Roma, Armando

Bion, W. R. (1972). Apprendere dall'esperienza, Roma, Armando

Blanco, I. M. (1975). It. Trad.: L'inconscio come insiemi infiniti. Torino, Einaudi.

Bucher, B., \& Lévi-Strauss, C. (1985). An Interview with Claude Lévi-Strauss, 30 June 1982. American Ethnologist, 
12(2), 360-368

Carli, R. (1987). Psicologia Clinica. Torino, UTET

Carli, R. (1994). Burnout, Collusione e Contesto Sociale. in Trombini G. (a cura di): Come Logora Curare. Bologna, Zanichelli

Chandler, D. (1994): Semiotics for Beginners. http://www.aber.ac.uk/media/Documents/S4B/semiotic.htm

Clarks, S. (1981). The foundation of Structuralism. A critique of Lévi-Strauss and the Structuralist Movement. The Harvester Press Limited, and Barnes \& Noble Books, 1981

Collisani, A. (1988). Musica e Simboli. Sellerio, Palermo, 1988

Corbey, R. (1991). Freud's Phylogenetic Narrative. In: Corbey R., Leerssen J. (eds), Alterity, Identity, Image, Selves and Others in Society and Scholarship. Amsterdam, Atlanta. Ga Rodopi, 1991: 37-56

Del-Ninno, M. (2010). Claude Lévi-Strauss: tra antropologia e semiotica. http://www.etnosemiotica.it/userfiles/DNM\%20LS\%20Tra\%20antropologia\%20e\%20semiotica_\%20Pdf\%20Taho ma.pdf

Ekstrom, S. R. (2004). The Mind beyond our immediate awareness: Freudian, Jungian, and cognitive models of unconscious. Journal of Analytical Psychology, 657-682; http://dx.doi.org/10.1111/j.0021-8774.2004.00494.x

Freud, S. (1899). It. Trad.: L’Interpretazione dei Sogni. Torino, Bollati Boringhieri, 1990

Freud, S. (1913). It. Trad.: Totem e Tabù. Roma, Newton Compton, 1992

Freud, S. (1927). It. Trad.: L'avvenire di un'illusione. Torino, Boringhieri, 1979

Freud, S. (1939). It. Trad.: Mosè ed il Monoteismo. Roma, Newton Compton, 2010

Graves, R. (1955). I Miti Greci. Milano, Longanesi \& C., 1983

Homer, S. (2005). Jaques Lacan. Routledge, 270 Madison Avenue, New York, NY 10016

Imberty, M. (1990). Le Scritture del Tempo. Semantica Psicologica della Musica. Ricordi, Milano, 1990

Jung, C. G. (1912). It. Trad.: La Libido, simboli e trasformazioni. Newton Compton 2006, Roma

Jung, C. G. (1936). It. Trad.: Il Concetto di Inconscio Collettivo. Torino, Bollati Boringhieri, 2011.

Jung, C. G. (1937). It. Trad.: Psicologia e Religione. Torino, Boringhieri, 1984

Jung, C. G. (1940). Psicologia dell'Archetipo del Fanciullo. In Jung C. G. e Kerény K., 1940-41. Prolegomeni allo Studio Scientifico della Mitologia. Ed. Italiana, Boringhieri, Torino, 1973

Kerény, K., (1959). Prometheus. Archetypal Image of Human Existence. Translated from the German by Ralph Manheim. Princeton University Press. Princeton, New Jersey, 1997

Kohl, M. (1995). The Nature of Promethean Ethics. Newsletter of the Centre of Applied Ethics, (Hong Kong) 3:1 (1995). 2-5; http://marvinkohl.com/pubs/doc10.pdf

Lacan, J. (1949). The Mirror Stage as formative of the I Function, as revealed in psychoanalytic experience. In: Jaques Lacan. Écrits (translated by Bruce Fink). W.W. Norton \& Company, New York - London, 2002; pagg.75-82

Lacan J. (1953a). Funzione e campo della Parola e del Linguaggio in Psicoanalisi. In Jaques Lacan. Scritti (a cura di G. B. Contri). Volume primo; Torino, Einaudi

Lacan, J. (1953b). On the Names of the Father. (Translated by B. Fink). Polity Press, Cambridge, 2013

Lacan, J. (1956). Seminar on "The Purloined Letter. In: Jaques Lacan. Écrits (translated by Bruce Fink). W.W. Norton \& Company, New York - London, 2002

Lacan, J. (1957). The instance of the letter in the Unconscious. In: Jaques Lacan. Écrits (translated by Bruce Fink). W.W. Norton \& Company, New York - London, 2002

Lacan, J. (1958). La Forclusione del Nome del Padre. In: J. Lacan. Seminario V. Einaudi, Torino. 2004 (a cura di A. Di Ciaccia).

Lacan, J. (1974). Press Conference by Doctor Jaques Lacan at the French Cultural Center, Rome, 29 October 1974. Lettres de l'École freudienne, 16.

http://braungardt.trialectics.com/sciences/psychoanalysis/jacques-lacan/press-conference-jacques-lacan-rome-29october-1974/

Lévi-Strauss, C. (1955a). The Structural Study of Myth. It. Trad.: Il Saggiatore, Milano 2009 
Lévi-Strauss, C. (1955b). Tristes Tropiques. It. Trad.: il Saggiatore, Milano 2008

Lévi-Strauss, C. (1962). La Pensée Sauvage, 1962 (it. Trad. 1964, Il Saggiatore, Milano 2015

Lévi-Strauss, C. (1964). Le cru et le cuit. It. Trad. : Il Crudo e il Cotto. Il saggiatore, Milano 2008;

Lévi-Strauss, C. (1967). Du Miel aux cendres. It. Trad. Dal Miele alle Ceneri, Il Saggiatore, 2008.

Lévi-Strauss, C. (1968). L'Origine des manières de Table. It Trad.: Il Saggiatore, Milano, 2010.

Lévi-Strauss, C. (1971). L'Homme Nu. It. Trad. L'Uomo Nudo. Il Saggiatore, Milano 2008

Lévi-Strauss, C. (1977). Myth and Meaning. Routledge Classics (new edition). Taylor \& Francis, London, 2005; http://www.pdf-archive.com/2013/09/18/cl-levi-strauss-myth-and-meaning/cl-levi-strauss-myth-and-meaning.pdf

Mehlman, J. (1972). The "Floating Signifier": from Lévi-Strauss to Lacan. Yale French Studies, n. 48, French Freud: Structural Studies in Psychoanalysis, 10-3. http://www.jstor.org/stable/2929621

Mills, J. (2012). Jung's metaphysics. International Journal of Jungian Studies, vol. 00, n. 00, month 2012: 1-25; http://dx.doi.org/10.1080/19409052.2012.67118

Orfanos, S. D. (2006). Mythos and Logos. Psychoanalytic Dialogues, 16(4), 481-499

Oyserman, D., Elmore, K., \& Smith, G. (2012). Self, Self-Concept, and Identity. In: Leary M. R., Tangney J. P.: Handbook of Self and Identity. Second edition (69-104). The Guildford press, New York - London, 2012.

Potschka, M. (2004). Sigmund Freud on phylogenic memory. ISSEI Conference "The Narrative of Modernity: Co-Existence of Differences". $9^{\text {th }}$ Conference of the International Society for the Study of European Ideas (ISSEI) in cooperation with the University of Navarro, Pamplona, Spain.

http://homepage.univie.ac.at/Martin.Potschka/papersISSEI2004/Potschka6d_a.pdf

Romagnoli E.: ESCHILO. Prometeo incatenato: http://www.filosofico.net/promincateneschilo42.htm

Sanasi/a P.: ESIODO. Le Opere e i Giorni: http://fluby.com/get/407883/Esiodo---Opere-e-Giorni-wwc01bgfd6.html

Sanasi/b P.: ESIODO. Teogonia: http://it.scribd.com/doc/112560532/Esiodo-Teogonia

Sanasi/c P.: PLATONE. PROTAGORA. http://www.ousia.it/SitoOusia/SitoOusia/TestiDiFilosofia/TestiPDF/Platone/Protagora.pdf

Sanasi/d P.: PLATONE. TIMEO. http://www.ousia.it/SitoOusia/SitoOusia/TestiDiFilosofia/TestiPDF/Platone/Timeo.pdf

Scarnera, P. (2011). Symmetric Logic and "Homeric inn to Demeter" modernity: motherhood constellation and adolescent separation-individuation. Rivista di Psicologia Clinica, 35-52. https://www.researchgate.net/publication/299532383_Symmetric_Logic_and_Homeric_inn_to_Demeter_modernit y_motherhood_constellation_and_adolescent_separation-individuation

Schore, A. N. (2000). Attachment and the regulation of the right brain. Attachment \& Human development, 2(1), 23-47. http://www.allanschore.com/pdf/SchoreAttachHumDev.pdf

Schneider, M. (1970). Il Significato della Musica. Rusconi, Milano.

Sels, N. (2011). Myth, Mind and Methaphor. On the Relation of Mythology and Psychoanalysis. Journal of the Jan Van Eyck Circle for Lacanian Ideology Critique, 4(2011): 56-70; http://hdl.handle.net/1854/LU-1983963

Singer, T. (2006). The neuronal basis and ontogeny of empathy and mind reading: review of literature and implications for future research. Neuroscience and Biobehavioral Reviews, 30(2006), 855-863.

http://dx.doi.org/10.1016/j.neubiorev.2006.06.011

Small, B., \& Jollands, N. (2006). Technology and ecological economics: Promothean technology, Pandorian potential. Ecological Economics, 56(2006), 343-358; Elsevier B.V. All rights reserved. http://dx.doi.org/10.1016/j.ecolecon.2005.09.013

Stein, E. (1917). It. Trad.: L’Empatia. Torino, Angeli.

Valgimigli, M., (1904). Eschilo: la Trilogia di Prometeo. Zanichelli, Bologna 1904

Vandermeersch, P. (2001a). Psychoanalytic Interpretations of Religions Texts. Some Basics. In: Kessler R. \& Vandermeersch P. (eds). God, Biblical Stories and Psychoanalytical Understanding. Frankfurt a. M., Peter Lang. http://www.rug.nl/research/portal/files/3095943/PVDM196PsychoBible.pdf

Vandermeersch, P. (2001b). Looking Back at Sodom. Psychoanalysis and Diachronic Reading. In: Kessler R. \& Vandermeersch, P. (eds). God, Biblical Stories and Psychoanalytical Understanding. Frankfurt a. M., Peter Lang. http://www.rug.nl/research/portal/files/3095943/PVDM196PsychoBible.pdf 
Van Haute, P. (2005). Psychoanalysis and/as Phylosophy? The Anthropological Significance of Pathology in Freud's "Three Essay on the Theory of Sexuality" and in the Psychoanalytic Tradition. Natureza Humana, 7(2), 359-374.

Vernant, J. P. (1987). Greek Religion. Trad. It: Mito e Religione in Grecia Antica. Donzelli, Roma, 2008.

Watzlavick, P., Eavin J. H., \& Jackson D. D. L. (1971). Pragmatica della Comunicazione Umana. Roma, Astrolabio

Wilber, K. (1989a). Lo Spettro dello Sviluppo. In: Wilber K., Engler J., Brown D. P., 1989 (eds). Le trasformazioni della coscienza. Roma, Ubaldini.

Wilber, K. (1989b). Lo Spettro della Psicopatologia. In: Wilber K., Engler J., Brown D. P., 1989 (eds). Le trasformazioni della coscienza. Roma, Ubaldini.

Wilber, K. (1989c). Modalità di Trattamento. In: Wilber K., Engler J., Brown D. P., 1989 (eds). Le trasformazioni della coscienza. Roma, Ubaldini.

\section{Notes}

Note 1. An example of comparison between similar myth, together a more extended discussions of literature, is furnished in:

Scarnera P. (2015). Madonna della Stella. Creare, regolare e curare le Comunità con le storie e con i luoghi. Armando, Roma 2015.

\section{(cc) $\mathrm{EY}$}

This work is licensed under a Creative Commons Attribution 3.0 License. 